\title{
Manganese(III) Complexes with Tetradentate Schiff Base Ligands: IR, UV/Vis, Electrochemistry and Fluorescence Properties
}

\author{
Naser Eltaher Eltayeb \\ Department of Chemistry, Rabigh College of Science and Arts, King Abdulaziz University, P.O. Box 344, Jeddah, Saudi Arabia
}

\section{*Corresponding author:}

email: netaha@kau.edu.sa; nasertaha90@hotmail.com

Received: May 30, 2019

Accepted: July 30, 2019

DOI: $10.22146 /$ ijc.46395

\begin{abstract}
Three trivalent manganese complexes have been synthesized, isolated, and characterized, namely, $\left[\mathrm{MnCl}\left(\mathrm{OH}_{2}\right)(\mathrm{Lx})\right] \cdot n \mathrm{H}_{2} \mathrm{O}$ (I-III). Lx is a tetradentate Shiff base ligand, where Lx =LI, 2,2'-\{1,2-phenylenebis [nitrilomethylylidene] \}bis(phenolate), LII, 2,2'-\{1,2-phenylenebis[nitrilomethylylidene]\}bis(5-methoxyphenolate), and LIII, 2,2'$\{1,2$-phenylenebis[nitrilomethylylidene]\}bis(4-methoxyphenolate), $n=1,1.5$ and 0 for I, II and III, respectively. These complexes were characterized using IR, elemental analysis and UV-Vis spectroscopy. In addition, the fluorescence, photoluminescence (PL), electrochemistry and thermal stability of these complexes were studied.
\end{abstract}

Keywords: manganese; Schiff base; electrochemistry; photoluminescence

\section{- INTRODUCTION}

Schiff base ligands attracted the attention of researchers for many decades because of their unique properties and their ease of synthesis and tailoring [1-5]. The coordination of Schiff base ligands with transition metals results in complexes with better properties in term of solubility, biological and catalytic activity [1-7]. Thus, organic-metal chelate complexes, in particular, have attracted a lot of attention. Manganese-Schiff base complexes are actively used as catalysts due to their ability to epoxidize unfunctionalized alkenes with high stereoselectivity [8]. The structural characterization of the manganese-Schiff base complexes used to improve enantioselectivity has been reported [9-10]. The MnSchiff base compounds exhibit the subtle changes to its property due to the nature of the axial ligands. Therefore, solvents used for crystallization give a significant impact to the crystal structure of the complex [11-12]. Organicmetal complexes of salicylaldehyde Schiff base ligands are expected to show good luminescent properties because its hydroxyl group and a coordinating nitrogen atom and a delocalized $\pi$-system [13-14].

In this paper, three ligands formed from the reaction of salicylaldehyde and its alkoxy substituents with $o$-phenylenediamine namely $\mathbf{L I}, 2,2^{\prime}-\{1,2$-phenylenebis [ni trilomethylylidene]\}bis(phenolate), LII, 2,2'-\{1,2-pheny lenebis[nitrilomethylylidene]\}bis(6-methoxyphenolate), LIII, 2,2'-\{1,2-phenylenebis[nitrilomethylylidene]\}bis(5methoxyphenolate), and their respective complexes with $\mathrm{Mn}(\mathrm{III})$ ion as well as their electrochemical and photoluminescent properties are presented.

\section{- EXPERIMENTAL SECTION}

\section{Materials}

All the chemicals and solvents used for the synthesis were reagent grade. Manganese chloride tetrahydrate, $\left[\mathrm{MnCl}_{2} \cdot 4 \mathrm{H}_{2} \mathrm{O}\right]$ (Acros), Salicylaldehyde (Acros), o-phenylenediamine (Merck), Triethylamine (Merck), 4-methoxysalicylaldehyde (Acros), and 5methoxysalicylaldehyde (Acros) were used as received.

\section{Procedure}

\section{Physical measurements}

Microanalyses $(\mathrm{CHN})$ were performed on a Perkin-Elmer 2400II elemental analyzer. Electronic spectra were obtained using a JASCO V-500 spectrophotometer for UV/VIS in solution and PerkinElmer lambda 35 for solid state. FT-IR spectra were recorded on Perkin-Elmer 2000 FT-IR with samples were prepared as $\mathrm{KBr}$ pellets. Electrochemical experiments were carried out using an Epsilon potentiostat with three-electrode configuration consisting of a platinum working electrode, a Pt wire as 
auxiliary electrode and $\mathrm{Ag} / \mathrm{AgCl}$ as the reference electrode and $0.1 \mathrm{~mol} \mathrm{dm}^{-3}$ tetrabutylammonium tetrafluoroborate as supporting electrolyte in DMF solution under dry nitrogen atmosphere with a scan rate of $0.1 \mathrm{~V} \mathrm{~s}^{-1}$. Data were collected using Epsilon EC-V160 software supplied by Bioanalytical. Fluorescence spectra were obtained using JASCO spectrofluorometer FP-750. Photoluminescence (PL) spectra were executed at room temperature by using Jobin Yvon HR800UV system. Thermal investigations (TGA/DGA) were carried out on a Perkin Elmer thermogravimetric analyzer TGA7 under nitrogen environment on heating rate $10{ }^{\circ} \mathrm{C} \mathrm{min}^{-1}$.

\section{Synthesis}

General method: using our previous method [1516], the complexes I-III were prepared by refluxing a mixture of the corresponding aldehyde $(4 \mathrm{mmol})$ [ $\mathbf{I}$, salicylaldehyde; II, 4-methoxysalicylaldehyde and III, 5methoxysalicylaldehyde], and $o$-phenylenediamine $(2 \mathrm{mmol})$, in ethanol $(20 \mathrm{~mL})$ in a $50 \mathrm{~mL}$ round-bottom flask equipped with a magnetic stir bar and a water-cooled reflux condenser for $30 \mathrm{~min}$. Then $\mathrm{MnCl}_{2} \cdot 4 \mathrm{H}_{2} \mathrm{O}(2 \mathrm{mmol})$ in 10 of $\mathrm{mL}$ ethanol was added, followed by the addition of $0.5 \mathrm{~mL}$ triethylamine. The mixture was stirred for three hours at room temperature. The brown precipitate obtained by filtration was washed with ethanol about $5 \mathrm{~mL}$, then washed by copious amount of diethyl ether, and dried at room temperature. The general scheme of chemical equations is illustrated in Fig. 1.

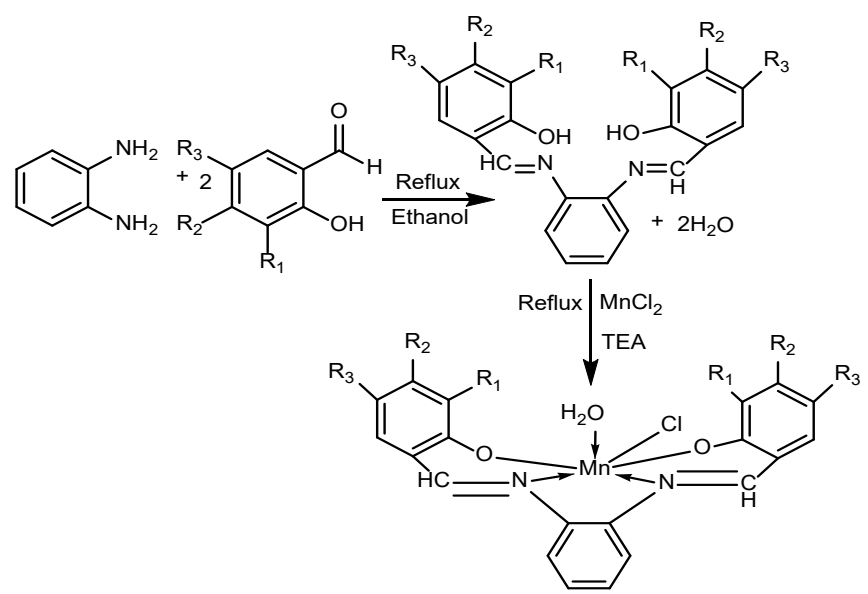

Fig 1. General scheme of synthesis of complexes I, II and III
Synthesis of aquachloro-2,2'-\{1,2-phenylenebis[ni trilomethylylidene]\}bis(phenolate)manganese(III)] $\mathbf{H}_{2} \mathbf{O}$, I. The complex was prepared by the general method, using salicylaldehyde, (yield: 0.519 g, 58.87\%, m.p. > $\left.300{ }^{\circ} \mathrm{C}\right)$. IR spectroscopy $\left(\mathrm{KBr}, \mathrm{cm}^{-1}\right): v(\mathrm{O}-\mathrm{H}) \mathrm{H}_{2} \mathrm{O} 3413$, $v(\mathrm{C}-\mathrm{H})$ aromatic 3016, $v(\mathrm{C}=\mathrm{N}) 1604, v(\mathrm{C}=\mathrm{C}) 1578,1537$, 1494. UV/Vis spectroscopy (in acetonitrile, $\lambda_{\max } \mathrm{nm}, \varepsilon$ $\left.\left(\mathrm{dm}^{3} \mathrm{~mol}^{-1} \mathrm{~cm}^{-1}\right)\right): 246\left(41.9 \times 10^{3}\right), 336\left(27.6 \times 10^{3}\right), 434$ $\left(10.2 \times 10^{3}\right)$. UV/Vis spectroscopy (solid, $\left.\lambda_{\max } \mathrm{nm}\right): 214$, 245, 327. Anal. Calc. For $\mathrm{C}_{20} \mathrm{H}_{16} \mathrm{ClMnN}_{2} \mathrm{O}_{3} \cdot \mathrm{H}_{2} \mathrm{O}: \mathrm{C}, 54.50$; $\mathrm{H}, 4.12$; N, 6.36, Mn, 12.46\%. Found: C, 54.27; H, 3.65; $\mathrm{N}, 6.53 ; \mathrm{Mn}, 12.94 \%$.

Synthesis of aquachloro-2,2'-\{1,2-phenylenebis [nitrilomethylylidene]\}bis(5-methoxyphenolate) manganese(III)] $1.5 \mathrm{H}_{2} \mathrm{O}$, II. The complex was prepared by the general method, using 4-methoxysalicylaldehyde, (yield: $0.773 \mathrm{~g}, 75.81 \%$, m.p. $>300{ }^{\circ} \mathrm{C}$ ). IR spectroscopy $\left(\mathrm{KBr}, \mathrm{cm}^{-1}\right): v(\mathrm{O}-\mathrm{H}) \mathrm{H}_{2} \mathrm{O} 3411, v(\mathrm{C}-\mathrm{H})$ aromatic 3007, $v(\mathrm{C}-\mathrm{H}) \mathrm{CH}_{3}$ 2938, 2837, v(C=N) 1619, v(C=C) 1598, 1573,1522 . UV/Vis spectroscopy (in acetonitrile, $\lambda_{\max }$ $\left.\mathrm{nm}, \varepsilon\left(\mathrm{dm}^{3} \mathrm{~mol}^{-1} \mathrm{~cm}^{-1}\right)\right): 254\left(30.58 \times 10^{3}\right), 347(28.43 \times$ $\left.10^{3}\right), 436\left(14.70 \times 10^{3}\right)$. UV/Vis spectroscopy (solid, $\lambda_{\max }$ $\mathrm{nm}): 238$, 252, 318, 361, 401. Anal. Calc. For $\mathrm{C}_{22} \mathrm{H}_{20} \mathrm{ClMnN}_{2} \mathrm{O}_{5} \cdot 1.5 \mathrm{H}_{2} \mathrm{O}$ : C, 51.83; H, 3.53; N, 5.49, Mn, 10.78\%. Found: C, 52.04; H, 3.64; N, 5.46; Mn, $11.11 \%$.

Synthesis of aquachloro-2,2'-\{1,2-phenylenebis [nitrilomethylylidene]\}bis(4-methoxyphenol)ma nganese(III)], III. The complex was prepared by the general method, using 5-methoxysalicylaldehyde (yield: 0.517 g, $53.54 \%$, m.p. $>300{ }^{\circ} \mathrm{C}$ ). IR spectroscopy ( $\mathrm{KBr}$, $\left.\mathrm{cm}^{-1}\right): v(\mathrm{O}-\mathrm{H}) \mathrm{H}_{2} \mathrm{O} 3475,3412, v(\mathrm{C}-\mathrm{H})$ aromatic 3023, $v(\mathrm{C}-\mathrm{H}) \mathrm{CH}_{3}$ 2939, 2833, v(C=N) 1618, v(C=C) 1601, 1580,1534 . UV/Vis spectroscopy (in acetonitrile, $\lambda_{\max } \mathrm{nm}$, $\left.\varepsilon\left(\mathrm{dm}^{3} \mathrm{~mol}^{-1} \mathrm{~cm}^{-1}\right)\right): 249\left(39.91 \times 10^{3}\right), 299\left(22.26 \times 10^{3}\right)$, $335\left(23.10 \times 10^{3}\right), 460\left(8.82 \times 10^{3}\right)$. UV/Vis spectroscopy (solid, $\lambda_{\max } \mathrm{nm}$ ): 236, 253, 311, 359, 402, 480. Anal. Calc. For $\mathrm{C}_{22} \mathrm{H}_{20} \mathrm{ClMnN}_{2} \mathrm{O}_{5}: \mathrm{C}, 54.73 ; \mathrm{H}, 4.18 ; \mathrm{N}, 5.80, \mathrm{Mn}$, $11.38 \%$. Found: C, 54.75; H, 3.63; N, 5.76; Mn, 10.91\%.

\section{- RESULTS AND DISCUSSION}

\section{Infrared Spectrum}

All the complexes show a broad band between $3424-3411 \mathrm{~cm}^{-1}$ in their infrared spectra, attributed to 
O-H stretching of coordinate/lattice water. Aromatic C$\mathrm{H}$ band appears between $3058-3007 \mathrm{~cm}^{-1}, \mathrm{C}=\mathrm{N}$ band appears between 1640-1604 $\mathrm{cm}^{-1}$ [17], and for all complexes, the $\mathrm{C}=\mathrm{N}$ band was shifted to higher wavenumbers than in free ligands, except $\mathrm{I}$ which may be due to the alkoxy substituent effect. Aromatic $\mathrm{C}=\mathrm{C}$ bands appear at their normal position between $1601-1494 \mathrm{~cm}^{-1}$, as shown in Fig. 2.

\section{Electronic Spectrum}

The electronic spectra of $\mathrm{Mn}$ (III) complexes in acetonitrile have mostly similar features, consisting of an intense band at 204-250 $\mathrm{nm}\left(49019.6-40000.0 \mathrm{~cm}^{-1}\right)$, bands of moderate-intensity at ca. 300-360 nm (33333.3$\left.27777.8 \mathrm{~cm}^{-1}\right)$ and one band or shoulder at $430-460 \mathrm{~nm}$ (23255.8-21739.1 $\mathrm{cm}^{-1}$ ) (Fig. 2). The first two bands can be assigned as $\pi$ to $\pi^{*}$ azomethane intraligand transition, while the third one can be assigned to phenolate $O(p \pi)$ to $\operatorname{Mn}\left(d \pi^{*}\right)$ ligand to metal charge transfer [18]. No d-d bands observed due to the presence of strong tail of the charge transfer band at lower energy. Electronic spectra of all the $\mathrm{Mn}$ (III) complexes in solid state show similar spectra to those obtained in acetonitrile except that the shoulder appearing in the region of 525-644 nm $\left(19047.62-15528.0 \mathrm{~cm}^{-1}\right)$, is either reduced or shifted to lower wavelength in acetonitrile (Fig. 3).

\section{Electrochemical Properties}

The electrochemical properties of I-III investigated by cyclic voltammetry (CV) in DMF solution, containing $0.1 \mathrm{M}$ tetrabutylammonium tetrafluoroborate as supporting electrolyte, using an $\mathrm{Ag} / \mathrm{AgCl}$ reference electrode under a dry nitrogen atmosphere with a scan

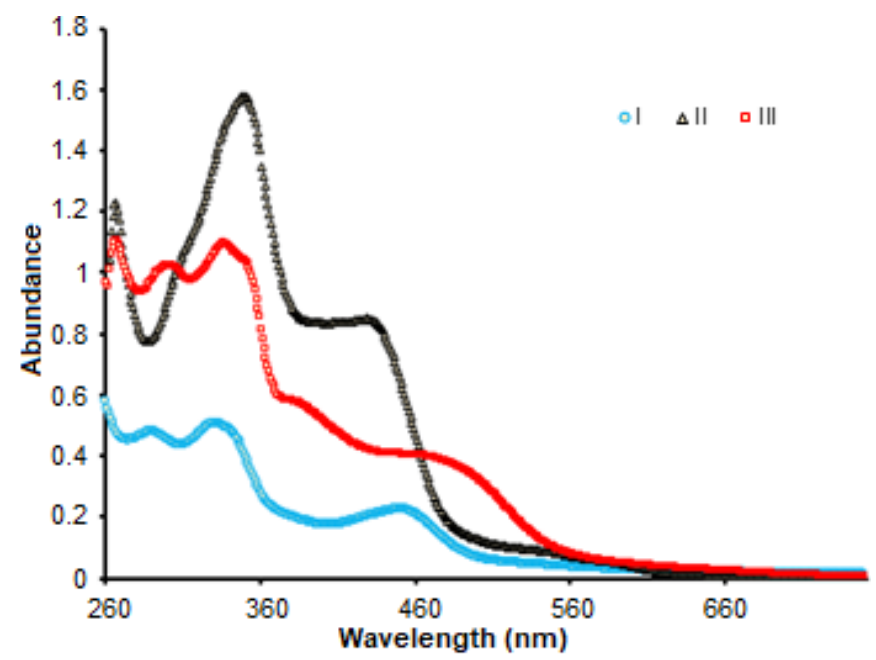

Fig 3. Electronic spectra of I, II and III (in acetonitrile, $\left.1.0 \times 10^{-6} \mathrm{M}\right)$

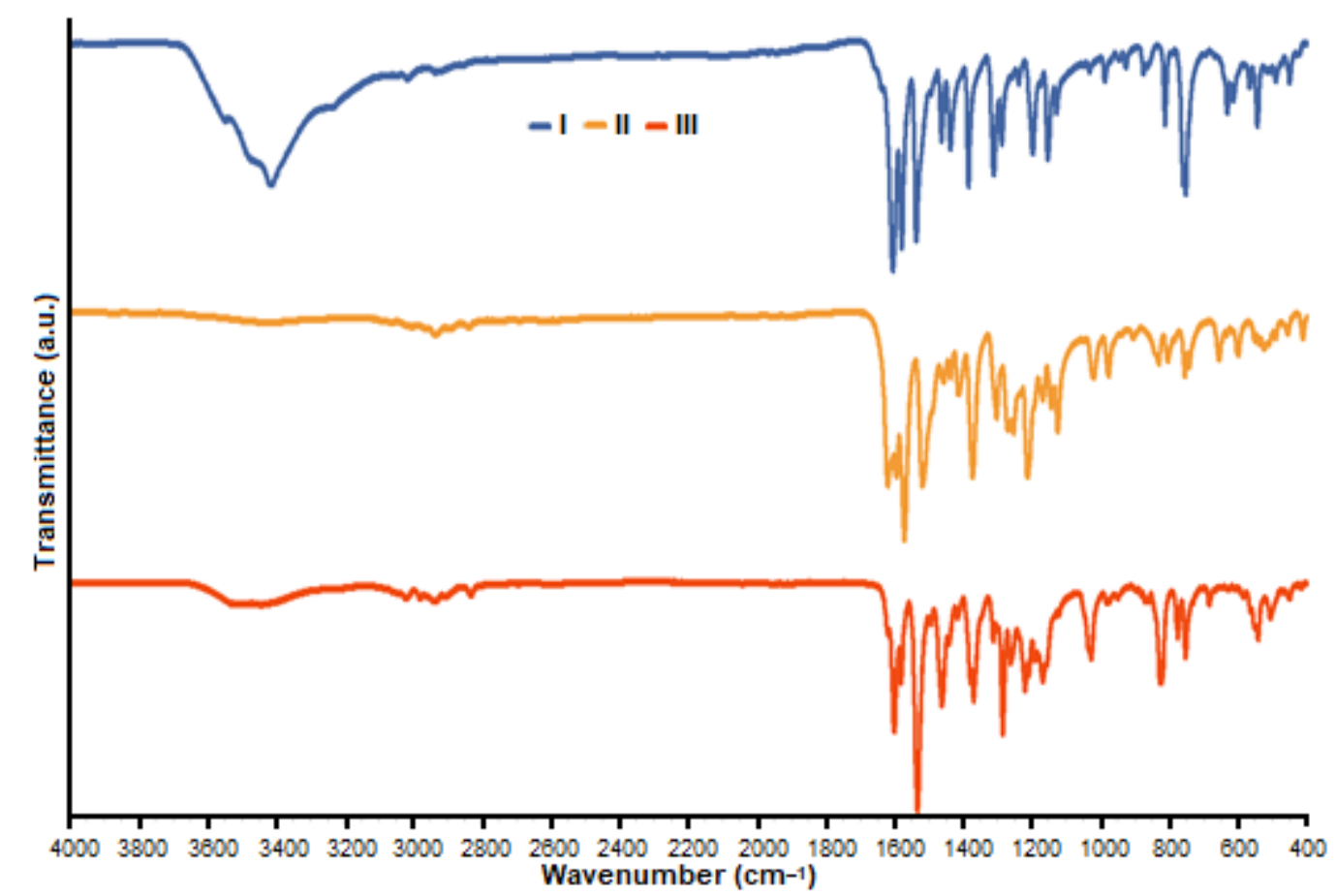

Fig 2. IR spectra of complexes I, II and III 
rate of $0.1 \mathrm{~V} \mathrm{~s}^{-1}$. Compounds I-III exhibit quasi-reversible reduction-oxidation wave, all the reduction peaks are observed at negative potentials (I - -0.217 , II -0.353 and III -0.325 ,), and all the oxidation peaks are observed at positive potential (I 0.061, II 0.096 and III 0.066) (Fig. 4 and Table 1). The quasi-reversible reduction-oxidation due to $\mathrm{Mn}^{3+} / \mathrm{Mn}^{2+}$ couple has been observed for previously reported complexes with similar ligand environment [18-20].

\section{Fluorescence Properties}

The fluorescence and photoluminescence spectra of compounds I-III, and their ligands LI-LIII are characterized by broad bands, in the region between 400-600 nm, typical of the intramolecular charge-transfer bands [21]. The photophysical data of the present systems in DMF are listed in Table 2 and showed in Fig. 5. The general feature, the blue shift in the range $(18-65 \mathrm{~nm})$ is observed in the fluorescence spectra in DMF compared with the photoluminescence spectra in the solid state, attributable to the DMF dielectric constant [22]. The other feature observed is the blue shift in the range 13$20 \mathrm{~nm}$ in compounds I, and II, in the fluorescence spectra, compare with their ligands. This blue shift may

Table 1. The electrochemical properties of I-III were investigated by cyclic voltammetry in acetonitrile

\begin{tabular}{ccccc}
\hline Compound & $\mathrm{E}_{\text {red }}(\mathrm{V})$ & $\mathrm{E}_{\text {ox }}(\mathrm{V})$ & $\mathrm{E}_{1 / 2}(\mathrm{~V})$ & $\Delta \mathrm{E}_{\text {ox-red }}$ \\
\hline I & -0.217 & 0.061 & -0.078 & 0.278 \\
II & -0.353 & 0.096 & -0.128 & 0.449 \\
III & -0.325 & 0.066 & -0.129 & 0.391 \\
\hline
\end{tabular}

Note: $\mathrm{E}_{1 / 2}=\left(\mathrm{E}_{\mathrm{ox}}+\mathrm{E}_{\text {red }}\right) / 2$

$\Delta \mathrm{E}_{\text {ox-red }}=\mathrm{E}_{\mathrm{pa}}-\mathrm{E}_{\mathrm{pc}}, \mathrm{V}$, where Epa and $\mathrm{Epc}$ are anodic and cathodic peak potentials, respectively

Table 2. The fluorescence and photoluminescence (PL) of compounds I-III and their respective ligands LI-LIII

\begin{tabular}{cccc}
\hline Compound & $\lambda_{\max }$ excitation & $\lambda_{\max }$ fluorescence & $\lambda_{\max } \mathrm{PL}^{*}$ \\
\hline I & 330 & 480 & 529 \\
LI & 396 & 500 & 534 \\
II & 330 & 472 & 537 \\
LII & 383 & 485 & 537 \\
III & 346 & 518 & 528 \\
LIII & 342 & 520 & 553 \\
\hline
\end{tabular}

Note: ${ }^{\star}$ all photoluminescence was obtained by excitation at $325 \mathrm{~nm}$

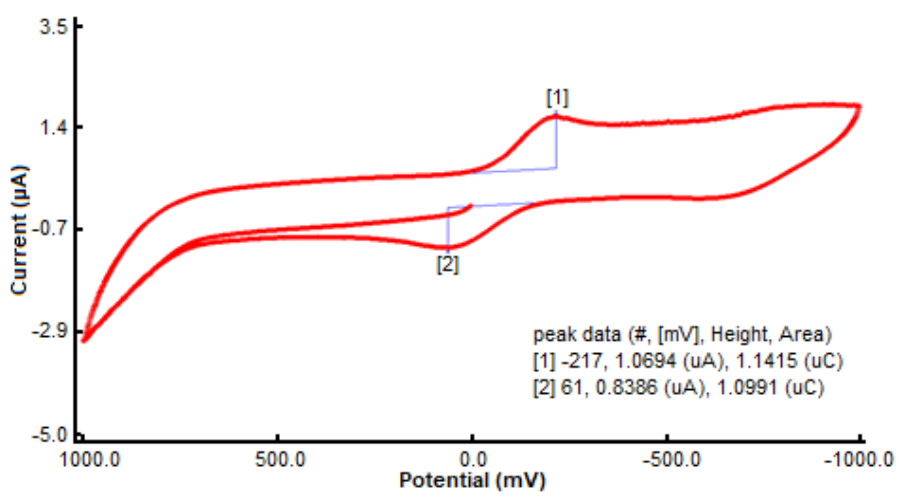

Fig 4. Cyclic voltammetry of compound I, in DMF with $0.1 \mathrm{~mol} \mathrm{dm}^{-1}$ tetrabutylammonium tetrafluoroborate as supporting electrolyte (working electrode, platinum; reference electrode, $\mathrm{Ag} / \mathrm{AgCl}$; Scan rate $100 \mathrm{mV} \mathrm{s}^{-1}$ )

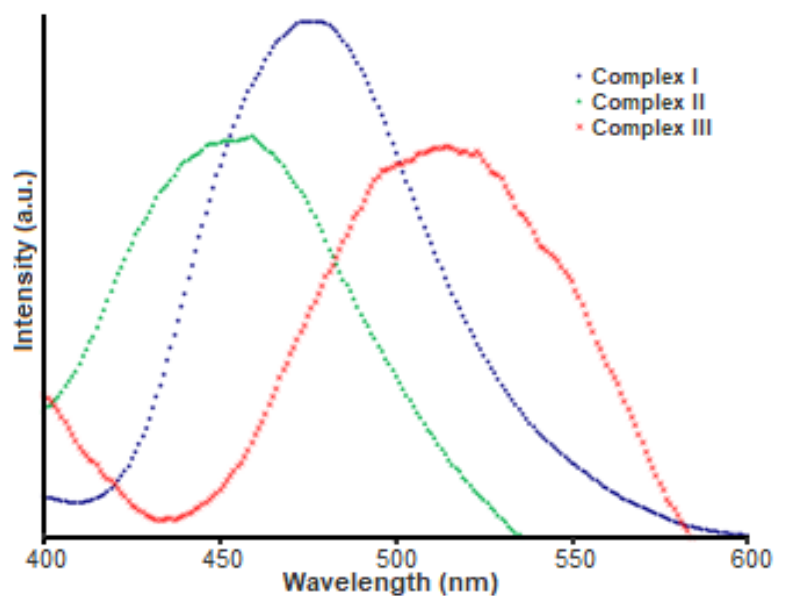

Fig 5. Fluorescence emission spectra of manganese complexes in solution 
be due to the effect of the coordination of $\mathrm{Mn}$ (III) with the ligands. This shift was not observed in the rest of the complexes because of high emission intensity of their ligands and its broaden band.

\section{Thermogravimetric Analysis}

The thermogravimetric analyses (TGA) of compounds
I-III were performed in the temperature range of 30$900{ }^{\circ} \mathrm{C}$ and under $\mathrm{N}_{2}$ atmosphere. All the complexes exhibited remarkable thermal stability and had an onset temperature for decomposition at about $260{ }^{\circ} \mathrm{C}$, after release of solvated and coordinated water. The results indicate that these complexes are thermally stable, and the details can be seen in Fig. 6 .
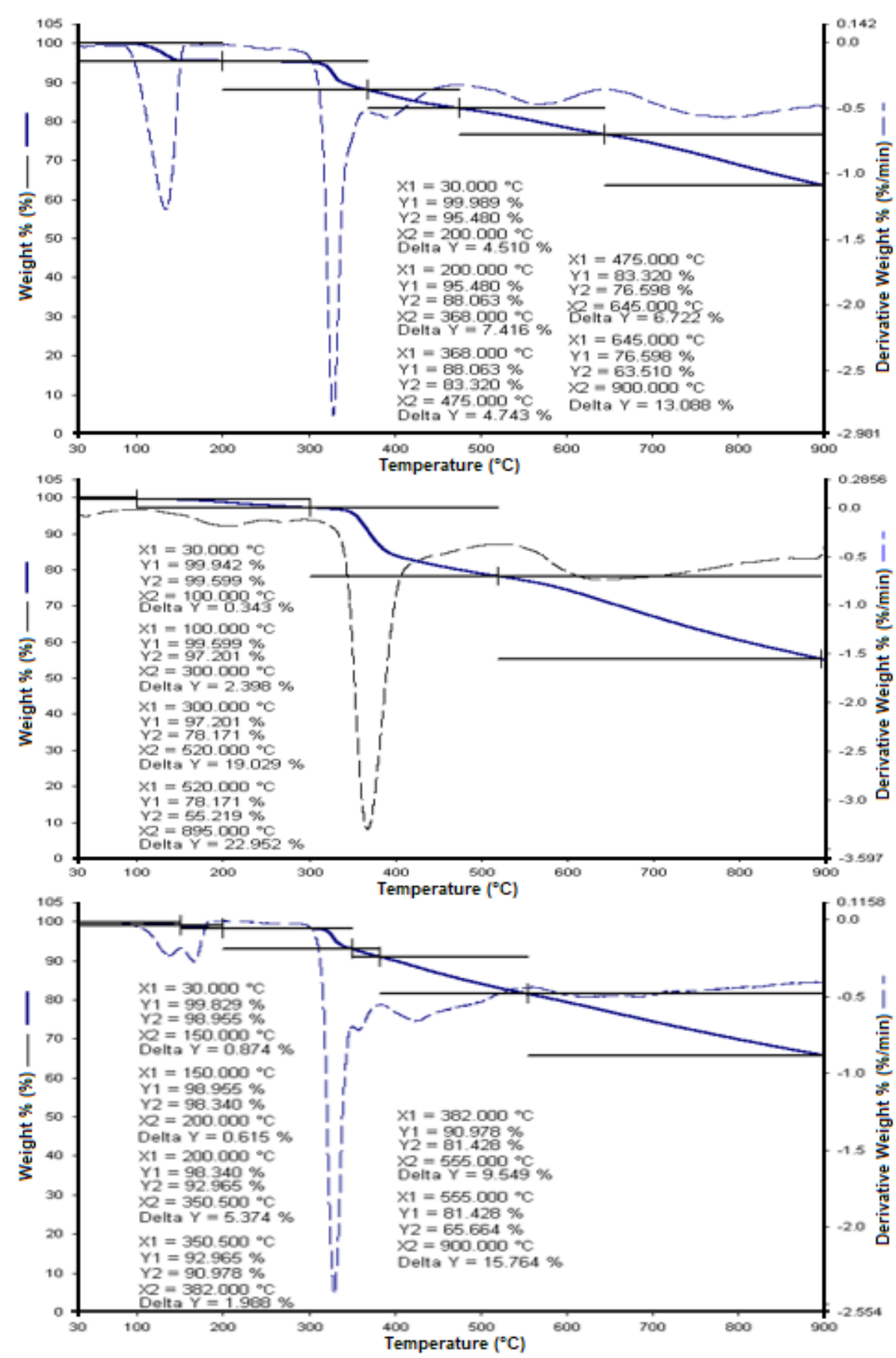

Fig 6. Thermogram of complexes I-III under nitrogen environment on heating rate $10{ }^{\circ} \mathrm{C} / \mathrm{min}$ 


\section{- CONCLUSION}

In this paper, three tetradentate Schiff base ligands and their Mn(III) complexes, namely, I, II and III, were successfully prepared through the coordination of $\mathrm{Mn}(\mathrm{III})$ to NONO in the ligand center. These complexes have been isolated and characterized using infrared spectroscopy (IR), elemental analysis (CHN), atomic absorption spectroscopy (AAS), and UV-Vis spectroscopy. In addition, the fluorescence, photoluminescence (PL), electrochemistry and thermal stability of these complexes were studied. The results showed that these complexes display fluorescence emission, reversible redox properties, and good thermal stability. From these studies, it can be concluded that the substitution position of the methoxy group affects the properties of these complexes and can be used to tune the optical properties of these complexes.

\section{- REFERENCES}

[1] Zhang, J., Xu, L., and Wong, W.Y., 2018, Energy materials based on metal Schiff base complexes, Coord. Chem. Rev., 355, 180-198.

[2] Kaczmarek, M.T., Zabiszak, M., Nowak, M., and Jastrzab, R., 2018, Lanthanides: Schiff base complexes, applications in cancer diagnosis, therapy, and antibacterial activity, Coord. Chem. Rev., 370, 42-54.

[3] Das, P., and Linert, W., 2018, Schiff base-derived homogeneous and heterogeneous palladium catalysts for the Suzuki-Miyaura reaction, Coord. Chem. Rev., 311, 1-23.

[4] Rezaeivala, M., and Keypour, H., 2014, Schiff base and non-Schiff base macrocyclic ligands and complexes incorporating the pyridine moiety - The first 50 years, Coord. Chem. Rev., 280, 203-253.

[5] Gupta, K.C., and Sutar, A.K., 2008, Catalytic activities of Schiff base transition metal complexes, Coor. Chem. Rev., 252 (12-14), 1420-1450.

[6] Eltayeb, N.E., Teoh, S.G., Kusrini, E., Adnan, R., and Fun H.K., 2010, The manganese(III) complex with chelating Schiff base ligand: X-ray structure, spectroscopic and computational studies, Spectrochim. Acta, Part A, 75 (1), 453-457.
[7] Paul, L., Banerjee, B., Bhaumik, A., and Ali, M., 2017, Catecholase activity of a manganese Schiff base complex functionalized over SBA- 15 in aqueous heterogeneous medium, Microporous Mesoporous Mater., 249, 78-87.

[8] Lane, B.S., and Burgess, K., 2003, Metal-catalyzed epoxidations of alkenes with hydrogen peroxide, Chem. Rev., 103 (7), 2457-2474.

[9] Linker, T., 1997, The Jacobsen-Katsuki epoxidation and its controversial mechanism, Angew. Chem. Int. Ed., 36 (19), 2060-2062.

[10] Korendovych, I.V., and Rybak-Akimova, E.V., 2004, Chloro\{2,2'-[(1S,2S)-1,2-diphenyl-1,2-ethane diylbis(nitrilomethylidyne)] diphenolato- $\kappa^{4} O, N, N^{\prime}$, $\left.\mathrm{O}^{\prime}\right\}$ (ethanol-kO)manganese(III), Acta Crystallogr., Sect. C: Cryst. Struct. Commun., 60 (2), m82-m84.

[11] Horwitz, C.P., Dailey, G.C., and Tham, F.S., 1995, Aquachloro[bis(5-chlorosalicylidene)ethylenediami nato]manganese(III), Acta Crystallogr., Sect. C: Cryst. Struct. Commun., 51 (5), 815-817.

[12] Martínez, D., Motevalli M., and Watkinson, M., 2002, Aquachloro[ $N, N^{\prime}$-ethylenebis(salicylideneimi nato)]manganese(III), Acta Crystallogr., Sect. C: Cryst. Struct. Commun., 58 (4), m258-m260.

[13] Shen, Y.Z., Gu, H., Pan, Y., Dong, G., Wu, T., Jin, X.P., Huang, X.Y., and Hu, H., 2000, Synthesis and characterization of dialkylgallium (dialkylindium) complexes of $\mathrm{N}$-salicylidene 2-aminopyridine and $\mathrm{N}$-salicylidene 2-methoxyaniline: Crystal structure of dimethyl[ $N$-salicylidene 2-aminopyridine] gallium, J. Organomet. Chem., 605 (2), 234-238.

[14] Chen, T.R., 2005, Luminescence and electroluminescence of bis (2-(benzimidazol-2-yl) quinolinato) zinc. Exciplex formation and energy transfer in mixed film of bis (2-(benzimidazol-2-yl) quinolinato) zinc and $N, N^{\prime}$-bis-(1-naphthyl)- $N, N^{\prime}$ diphenyl-1,1'-biphenyl-4,4'-diamine, J. Mol. Struct., 737 (1), 35-41.

[15] Eltayeb, N.E., Teoh, S.G., Chantrapromma, S., Fun, H.K., and Adnan, R., 2008, Chlorido \{5,5'-dimethoxy -2,2'-[1,2-phenylenebis(nitrilomethylidyne)]dipheno lato- $\left.\kappa^{4} O, N, N^{\prime}, O^{\prime}\right\}$ manganese(III), Acta Crystallogr., 
Sect. E: Struct. Rep. Online, 64, m670-m671.

[16] Eltayeb, N.E., Teoh, S.G., Chantrapromma, S., Fun, H.K., and Ibrahim, K., 2007, Chlorido\{4,4'-dimethoxy -2,2'-[1,2-phenylenebis(nitrilomethylidyne)]dipheno lato\}methanolmanganese(III), Acta Crystallogr., Sect. E: Struct. Rep. Online, 63 (12), m3193-m3194.

[17] Silverstein, R.M., Bassler, G.C., and Morrill, T.C., 1991, Spectrometric Identification of Organic Compounds, $5^{\text {th }}$ Ed., John Wiley \& Sons, Inc., Chichester, England.

[18] Biswas, S., Mitra, K., Schwalbe, C.H., Lucas, C.R., Chattopadhyay, S.K., and Adhikary, B., 2005, Synthesis and characterization of some $\mathrm{Mn}$ (II) and $\mathrm{Mn}$ (III) complexes of $N, N^{\prime}$-o-phenylenebis(salicyli deneimine) $\left(\mathrm{LH}_{2}\right)$ and $N, N^{\prime}$-o-phenylenebis (5-bromo salicylideneimine $\left(\mathrm{L}^{\prime} \mathrm{H}_{2}\right)$. Crystal structures of $\left[\mathrm{Mn}(\mathrm{L})\left(\mathrm{H}_{2} \mathrm{O}\right)\left(\mathrm{ClO}_{4}\right)\right],[\mathrm{Mn}(\mathrm{L})(\mathrm{NCS})]$ and an infinite linear chain of $[\mathrm{Mn}(\mathrm{L})(\mathrm{OAc})]$, Inorg. Chim. Acta, 358 (8), 2473-2481.

[19] Panja, A., Shaikh, N., Ali, M., Vojtíšek, P., and
Banerjee, P., 2003, Structural characterization of a new manganese(III)-salen complex $\left[\mathrm{H}_{2} \mathrm{salen}=N, N^{\prime}\right.$ bis(salicylidene)ethane-1,2-diamine] and study of its electron transfer kinetics with hydroquinone and catechol, Polyhedron, 22 (9), 1191-1198.

[20] Maneiro, M., Bermejo, M.R., Sousa, A., Fondo, M., González, A.M., Sousa-Pedrares, A., and McAuliffe, C.A., 2000, Synthesis and structural characterisation of new manganese(II) and (III) complexes. Study of their photolytic and catalase activity and X-ray crystal structure of [Mn(3-OMe, 5-Br-salpn)(EtOH) $\left.\left(\mathrm{H}_{2} \mathrm{O}\right)\right] \mathrm{ClO}_{4}$, Polyhedron, 19 (1), 47-54.

[21] Asher, S., and Sauer, K., 1976, Resonance Raman spectroscopy of $\mathrm{Mn}$ (III) etioporphyrin I at the $\pi \rightarrow \pi^{*}$ and charge transfer bands: The use of charge transfer bands to monitor the complexation state of metalloporphyrins, J. Chem. Phys., 64 (10), 4115.

[22] Guilbault, G.G., 1973, Practical Fluorescence: Theory, Methods, and Techniques, Marcel Dekker, Inc., New York. 